\title{
CMA's new mission and vision statements rankle some members
}

- Cite as: CMAJ 2017 September 11;189:E1155-6. doi: 10.1503/cmaj.1095480

Posted on cmajnews.com on Aug. 20, 2017.

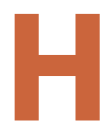

ow is it possible that the word "physician" doesn't appear in either the vision statement or the mission statement of the national association that represents Canadian physicians? This question was asked by doctors again and again during a session discussing the new strategic plan of the Canadian Medical Association (CMA) at its 150th annual general council in Quebec City.

"I belong to the Canadian Medical Association, not the Canadian Health Association or the Canadian Advocacy Association or even the Canadian Patient Association. I realize all of these things are important, but at root, we are a physician association," said Dr. Barbara Blumenauer of Kamloops, British Columbia. "Physicians have to be part of the mission statement. I'm almost offended that they aren't."

The mission statement of the CMA's new strategic plan, called CMA 2020, is "Empowering and caring for patients." The vision statement is "A vibrant profession and a healthy population." The absence of the word "physician" sends a mixed message to CMA members, according to Dr. David May of Powell River, BC.

"I think, of all the medical organizations, the CMA must be seen to have my back as a busy family doctor," said May, to much applause from the audience.

Indeed, the CMA's message is "not crystal clear," agreed Dr. Clover Hemans of Oakville, Ontario. "I want to feel comfortable that, across the nation, physicians are united in knowing our nation organization looks after our interests."

Hemans said she would "take a bullet" for her patients and is dedicated to meet-

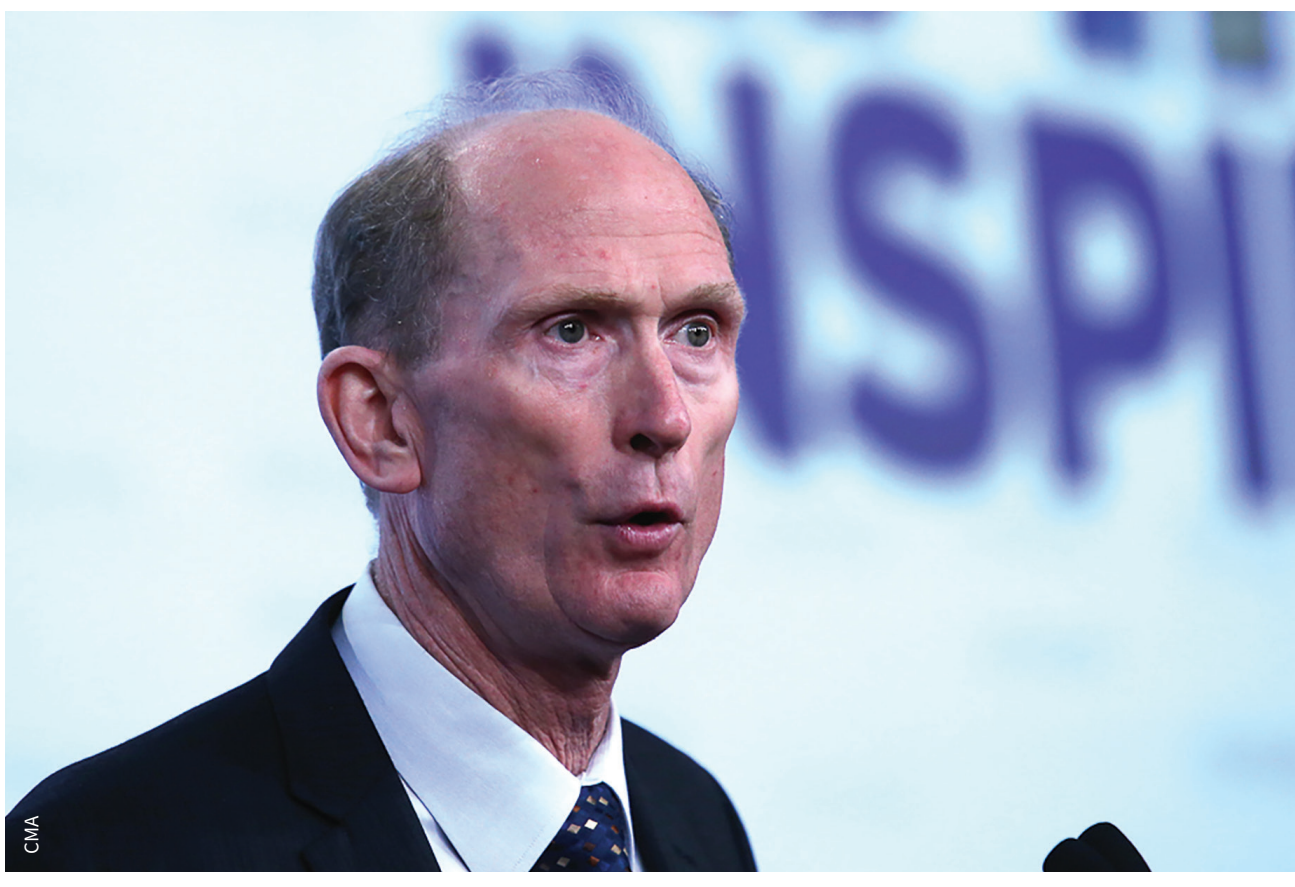

The CMA's new patient-centred strategic plan is not an abandonment of focusing on the needs of the association's physician members, said Dr. Brian Brodie, chair of the CMA board of directors.

ing all their needs, "but the CMA has to be there for me."

Removing the word "physician" from the CMA's mission and vision represents a "fundamental change in our core mandate, which I think would be a mistake," said Dr. Caroline Wang from Vancouver, $B C$. But even more important than focusing on words is focusing on action, said Wang. Like many doctors, she is concerned about the medical profession and the health care system.

"We must move beyond rhetoric to action," said Wang. "I didn't hear anything about clear goals and specific steps and strategies, including implementation and evaluation, to know whether we are getting closer to our goals and how we are doing."
Though many CMA members appeared concerned about the association's adoption of a patient focus, Dr. Brian Brodie, chair of the CMA board of directors, assured delegates at the annual meeting that they had nothing to worry about.

"In CMA 2020, we recognize that advocacy is our core business. Have we abandoned our focus on members? Of course not," Brodie said in his speech before the question-and-answer session. "It is impossible to not be pro-physician if you're pro-patient."

Brodie described CMA 2020 as a journey to find the words to express the purpose of the medical profession. As technologies such as genetic engineering, artificial intelligence and nanotechnology 
threaten to disrupt that profession, it will only become more important for physicians to understand who they are, what they do and why they do it, he said.

"The Internet, with its ease of access to information and social media platforms, has replaced many of the benefits that associations like ours used to offer," said Brodie. "We will need the CMA more than ever to connect ourselves and advocate for the patient."

The purpose of an organization like the CMA is to bring doctors together and help them find meaning in their work, to make them feel they are part of something bigger, said Brodie. It's about sharing ideas, rallying support for important causes, and charting the course of the profession, he said, adding that focusing on patients is vital to the CMA's mission. Some ideas the CMA are considering to engage patients better include forming patient councils and creating several positions on the board of directors for patients.

"The CMA of past may have offered an anchor of certainty in changing or turbu- lent times, but in order to navigate the storm, you need a map and you need a rudder. The map is the patient and the rudder is the CMA."

Rather than focusing on the exact wording used in the strategic plan, some in the audience applauded the CMA for putting more focus on patients. Among them was Dr. Anthea Lafreniere of Ottawa, who said the plan "resonates with me" because our "raison d'être is patients."

Roger Collier, CMAJ 